\title{
Meat Adulteration at Khulna City of Bangladesh: A Criminological Analysis
}

\author{
Md. Mahfuzur Rahman ${ }^{1 *}$, Hasibul Hossain Sumon ${ }^{2}$ \\ ${ }^{1,2}$ Lecturer, Department of Law, Faculty of Liberal Arts and Human Science, North Western University, \\ Khulna, Bangladesh
}

*Corresponding Author: Md. Mahfuzur Rahman, Lecturer, Department of Law, Faculty of Liberal Arts and Human Science, North Western University, Khulna, Bangladesh

\begin{abstract}
The right to food is closely related to right to life and for securing this right food safety is essential. Meat is a vital element of our food menu as well as a great source of protein also. It is really unfortunate that this great source of protein has become unsafe for us due to adulteration. The ultimate goal of this study is to search into the level of meat misbranding and adulteration from slaughter-houses that introduce unsafe food products to the consumer which is an indirect criminal activity according to various laws and legislations relating to the safety of food. Consumer awareness and food safety involve with a wide area of public interest about food safety issues. In this study, 16 (sixteen) slaughterhouses and 73 (seventy three) meat shops were selected from 18 markets in Khulna municipal area to collect data through a well structured questionnaire. The information was collected to evaluate the way of fraudulent activity of sellers related about meat. Results have shown a significant percentage of illegal practices done in slaughterhouses in Khulna city area. The slaughter houses are mostly found un-hygienic and certain chemicals also get mixed with meat causing danger to consumers. It is also observed that 5 slaughter-houses among 16 are involved in this type of illegal activity. An integrated and systems-based approach to food protection must be encompassed in both food safety and food defense which are imperative for ensuring the integrity of our food supply.
\end{abstract}

Keywords: Meat Adulteration, Criminological Aspects, Khulna, Slaughterhouse

\section{INTRODUCTION}

Food is essential for every living being on earth. Food can be defined as `edible or potable substance (usually of animal or plant origin), consisting of nourishing and nutritive components such as carbohydrates, fats, proteins, essential mineral and vitamins, which (when ingested and assimilated through digestion) sustains life, generates energy, and provides growth, maintenance, and health of the body.[1]

An unhygienic faulty food supply system is vulnerable to various types of contamination and adulteration. Consumers expect food to be fresh, good looking, nutritious, wholesomeness. Consumers could be victim of food poisoning, food adulteration and food frauds, misleading regarding food content (labeling), misleading indications, misleading descriptions, misleading pictures, food packaging.[2]

As per the section 3(5) of the Pure Food Ordinance, 1959(amended in 2005)[3] - "Food" means any kind of edible oil, fish, fruit, meat or vegetable or any other article used as food, drinking water or any other drink for human consumption other than any drug, and includes ice, aerated water, carbonated water or any substance whether processed, semi processed or raw or any substance which has been used in the manufacture, preparation or treatment of food and those articles which will be notified by the Government from time to time, and

- any substance which is intended for use in the composition or preparation of food,

- any permitted flavouring matter or any spice or condiment, and

- any food grade colouring matter, preservative, anti oxidant and other additives intended for use in food;' 
On the other hand the word 'adulterate' implies an element of deceit. According to the definition of Chamber's Dictionary it means 'to debase, falsify by mixing with something inferior or spurious'. [4]

Hence, the term 'food adulteration' can be simply defined- as an act of intentional debasing the quality of food offered for sale either by the admixture or substitution of inferior substances or by the removal of some valuable ingredient.

The meaning of adulteration varies from country to country on the basis of municipal law. If a food exceeds tolerances and regulatory limits of the country, it will be considered adulterated. It is to be noted that the basic contention of the term 'food adulteration' is fully relevant and inter-related with the terms/factors like 'food safety' and 'food security'.[5]

Though the word 'adulteration' has not been defined in anywhere of the laws prescribed in Bangladesh. Nonetheless, by the practices, food adulteration in Bangladesh means adding harmful chemicals, toxic colors or harmful additives with the food. Section 3(1) of The Pure Food Ordinance, 1959 has disclosed under its clauses (a) to (h), eight circumstances under which an article of food shall be deemed to be "adulterated" if-

- any substance has been mixed and packed with it so as to reduce or lower or injuriously affect its quality or strength, or

- any substance has been substituted wholly or in part for it, or

- any of the normal constituents has been wholly or in part abstracted so as to render it injurious to health, or

- it is mixed, coloured, powdered, coated or stained in a manner whereby damage or inferiority is concealed, or

- it does not comply with any standard provided by or under this Ordinance or any other law for the time being in force, or

- it contains or is mixed or diluted with any substance in such quantity as is to the prejudice of the purchaser or consumer or in such proportion as diminishes in any manner the food value or nutritive qualities which it possesses in its pure, normal, undeteriorated and sound condition, or

- it contains any poisonous or deleterious ingredient including radiation which may render it injurious to health, or

- it is not of the nature, substance or quality which it purports to be or which it is represented to be by the manufacturer or the seller;'

Then it is said that if meat is fallen into the above circumstances then such meat will be adulterated and then it will be termed as meat adulteration. Therefore, Meat adulteration may occur through physical, chemical or biological hazards and it could result in significant morbidity and mortality, economic and trade consequences, a strain on our public health systems, and political instability.

The WHO estimated that $80 \%$ of premature heart disease, stroke, and type 2-diabetes and $40 \%$ of cancer could be prevented through a low meat healthy diet, regular exercise, and avoidance of tobacco products. Improper or mislead labeling of meat can also harm consumer interests, which may be considered as a food crime.[6] It is therefore necessary to adopt community rules on the use of nutrition and health claims on foods as studies show that the consumers are most worried about food and drugs adulteration, swindles and food contamination.

This article has focused on a level of meat adulteration through the criminological activities of slaughterhouses within Khulna metropolitan areas where different types of illegal methods of processing, misbranding and adulteration of meat occurred. Such as-

Inter-species meat adulteration- Inter-species meat adulteration is common in many parts of the world and deceives consumers by replacing expensive meats with cheaper alternatives.[07] The substitutions generally practiced are mutton for goat meat, beef for buffalo meat, rabbit meat for chicken etc.[08] 
Water mixing in meat during selling- Meat is injected with water, but some water is absorbed during cooling in a chill-tank. During processing, recently slaughtered animal carcasses and their organ meats (hearts, livers, kidneys, etc.) are chilled to cool them down to a safe temperature.[09]

Low quality part of meat through hiding consumer concerns- The substitution of low quality part of meat with superior quality is a very common practice in many parts of the world. Article (13.2) of Slaughterhouse and Meat Inspection Act (SMIA), 1999 prescribes that no substance shall be mixed to change the obvious quality or taste, or to increase the weight of meat is forbidden.

Chemical adulterants in meat- Chemical ingredients are used to improve juiciness or tenderness, enhance flavor, improve color, stabilize color, increase shelf-life, improve safety, or increase waterholding capacity in meat.

Taking all of those in consideration our research has focused to investigate the level of meat misbranding and adulteration from slaughterhouses through different ways of criminal activities in Khulna municipal area.

\section{Materials AND Methods}

\subsection{Study Design}

The study was a cross-sectional study which focused on the criminological aspects of food misbranding in Bangladesh through meat (beef) by the slaughterhouses and meat shops. This study was conducted to build awareness among consumers to protect their right and health.

\subsection{Place of Study}

The study considered covering Khulna, a divisional city of Bangladesh. Study was conducted in Khulna municipal area to measure the level of meat adulteration and misbranding. From 18 markets 73 meat shops and 16 slaughterhouses were selected through purposive sampling procedure for this study.

\subsection{Study Period}

The study was conducted during April 2017 to January 2018. During this period standard questionnaire development, data collection, data entry, data analysis and report writing has been completed.

\subsection{Data Collection}

Most of the important material used for the study was a set of interview schedule. For assessing the existing management system a face to face questionnaire interview was carried out among the different representative of slaughterhouses in the study location. In addition, the final conclusion was drawn after paying personal visit to the spot throughout the study period. For conducting that specific interview and data collection the representative from slaughterhouses were separated on the basis of reconnaissance survey.

\section{RESUlT AND DisCUSSION}

Meat adulteration involves a wide area of public interest. Because of its high commercial value, meat attracted the attention of adulterators for centuries. Meat may be adulterated by sellers in many ways. Such as- inject water to increase weight of the product; practice to give lower weight than legal one; mix other low valued species meat with high valued species like buffalo meat with beef; practice to give low quality part of meat through hiding consumers concerns; unhygienic method from slaughter to sell point; use blood or other chemicals to represent to the consumers like a fresh product; improper sanitation or cleaning process into slaughterhouses etc.

\subsection{Mixing Low Valued Species Meat with High Valued Species Meat and Low Weight Giving Tendency}

The number of slaughterhouses who mixed low quality meat with high quality meat (like meat from buffalos with cow's meat) in their business is about $43.75 \%$ and which is almost fifty percentages of 
all slaughterhouses. About $56.25 \%$ of slaughterhouses does not involve with that type of fraudulent activity. Table-1 shows the percentages of slaughterhouses practice to mix low valued species meat with high valued species meat.

Table1. Mixing low valued species meat with high valued species meat $(n=16)$

\begin{tabular}{|c|c|c|}
\hline Mixing low valued species meat with high valued meat & Number & Percentage \\
\hline Yes & 07 & 43.75 \\
\hline No & 09 & 56.25 \\
\hline Total & 16 & 100 \\
\hline
\end{tabular}

On the other hand, the meat shops give lower weight than the legal weight during selling process. $58.90 \%$ of meat shops practice this kind of misdeeds in Khulna municipal area and $41.10 \%$ of sellers did not practice to give low weight to their consumers during selling operations.

Table2. Low weight giving tendency $(n=73)$

\begin{tabular}{|c|c|c|}
\hline Low weight giving tendency & Number & Percentage \\
\hline Yes & 43 & 58.90 \\
\hline No & 30 & 41.10 \\
\hline Total & 73 & 100 \\
\hline
\end{tabular}

\subsection{Water Mixing Tendency in Meat during Selling Periods}

Among different types of fraudulent activity in slaughterhouses against to the right of consumer, amount of water feed before slaughter and amount of water mixed after slaughter to increase weight of meat is significantly important. About $18.75 \%$ (Table 2) of slaughterhouses use less than 10 liter of water for each cattle. About $25 \%$ of slaughterhouses use 10 to 20 liter of water for each cow. A significant number $(31.25 \%)$ of sellers use more than 20 liter of water to weight gain of lean meat. This study also found that $25 \%$ of slaughterhouse is not involved with adding water.

Table3. Amount of water mixing in meat during selling periods $(n=16)$

\begin{tabular}{|c|c|c|}
\hline Amount of water mixed for each animal & Number & Percentages \\
\hline No mix of water & 04 & 25 \\
\hline Less than 10 liter & 03 & 18.75 \\
\hline 10-20 liter & 04 & 25 \\
\hline More than 20 liter & 05 & 1.25 \\
\hline Total & 16 & 100 \\
\hline
\end{tabular}

\subsection{Pushing Hormonal Injections}

It is really a threatening issue that before slaughtering hormonal injections are pushed by the sellers to the cows to increase its weight though it is a deadly measure taken by the sellers. Many sellers have mentioned after injecting if the cow is not slaughtered within 8-10 hours then the cow may die. Though this practice is confidential but this practice was observed in 2 slaughter houses upon 10-12 cows during this study.

Table4. Pushing hormonal injections $(n=16)$

\begin{tabular}{|c|c|c|}
\hline Pushing hormonal injections & Number & Percentages \\
\hline Yes & 02 & 12.50 \\
\hline No & 14 & 87.50 \\
\hline Total & 16 & 100 \\
\hline
\end{tabular}

\subsection{Hygienic Practices}

Adoption of hygienic practices before or after slaughter is very important activity to safe consumption of meat and meat products. Clean and safe water must be used to wash meat and handler.

According to the data presented in the table below shows that about $87.50 \%$ of slaughterhouses did not practice hygienic methods and hygienic equipments like knives, hand gloves, sanitizer etc. But $12.50 \%$ of slaughterhouses used hygienic method during their activity. 
Table5. Numerical Distribution of Slaughterhouses whether they follow Hygiene practices or not $(n=16)$

\begin{tabular}{|c|c|c|}
\hline Practice hygiene method & Number & Percentage \\
\hline Yes & 02 & 12.50 \\
\hline No & 14 & 87.50 \\
\hline Total & 16 & 100 \\
\hline
\end{tabular}

\subsection{Low Quality Meat Adding Tendency in Selling Process}

Another type of fraudulent activity with meat from meat shops is undeclared part of meat into the consumer bag. Through hiding process from customers a large number of meat shops practice to give low quality meat and is about $43.84 \%$ (Table 6 ).

Table6. Low quality meat adding tendency in selling process $(n=16)$

\begin{tabular}{|c|c|c|}
\hline Low quality meat adding tendency & Number & Percentage \\
\hline Yes & 32 & 43.84 \\
\hline No & 41 & 56.16 \\
\hline Total & 73 & 100 \\
\hline
\end{tabular}

\subsection{Chemical Adulterants used in Meat}

The figure-1 represents an overall percentage about chemicals added in meat. There are many chemicals used in meat (beef) among them sodium phosphate; sodium chloride; nitrate \& nitrite and cleaner \& sanitizer were observed in this study. According to the result, about $31.25 \%$ (Fgure-1) of slaughterhouses use these types of chemical additives and involved with that type of criminal activity. About $68.75 \%$ of slaughterhouses do not use this type of chemicals in their slaughterhouses.

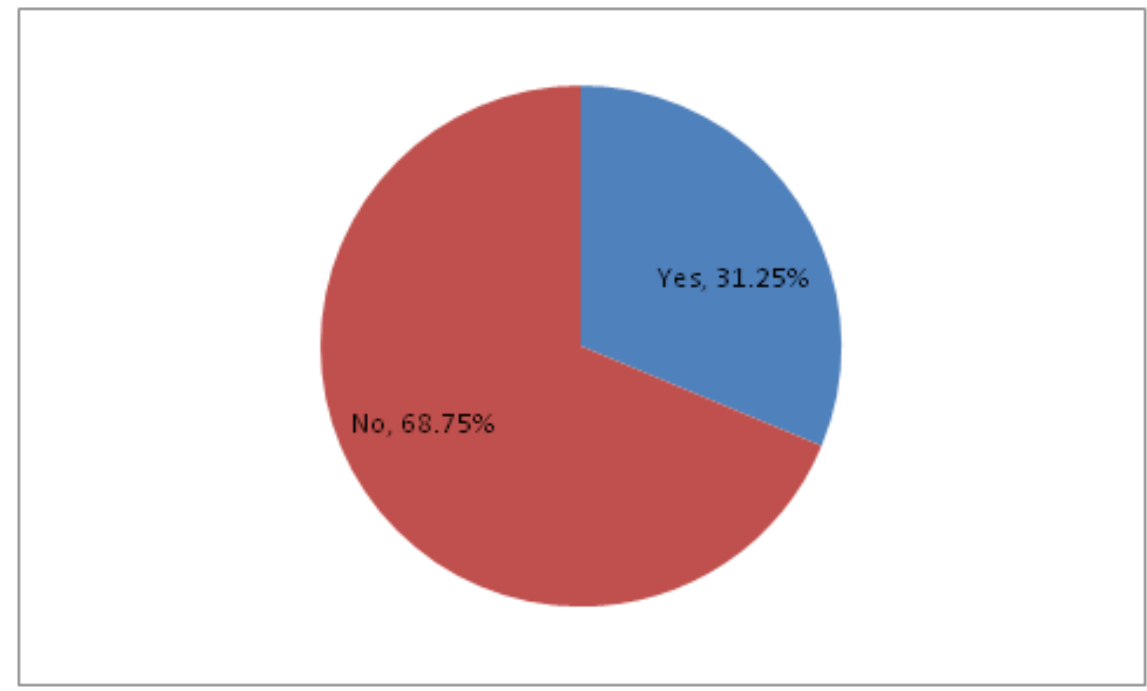

Figure1. Chemical adulterants used in meat $(n=16)$

\subsection{Number of Slaughterhouse with Specific Chemical Use}

Table below showed the number of slaughterhouses used specific chemical additives in their day-today selling of meat. It is observed that sodium phosphate is used by two slaughterhouses; cleaner \& sanitizer are used by three slaughterhouses; nitrate \& nitrite are used by one slaughterhouse and sodium chloride is also used by two slaughterhouses.

Table7. Identification number of slaughterhouses with specific chemical use

\begin{tabular}{|c|c|c|c|c|}
\hline Slaughterhouse & \multicolumn{4}{|c|}{ Chemical adulterants } \\
\cline { 2 - 5 } Identification no. & Sodium phosphate & Cleaner and Sanitizer & Nitrate and nitrite & Sodium chloride \\
\hline 04 & $\sqrt{ }$ & $\times$ & $\times$ & $\times$ \\
\hline 06 & $\times$ & $\sqrt{ }$ & $\times$ & $\times$ \\
\hline 09 & $\sqrt{ }$ & $\times$ & $\sqrt{ }$ & $\times$ \\
\hline 12 & $\times$ & $\sqrt{ }$ & $\times$ & $\times$ \\
\hline 14 & $\times$ & $\sqrt{ }$ & $\sqrt{ }$ & $\times$ \\
\hline
\end{tabular}




\subsection{Percentage Distribution of Different Chemicals used in Meat by the Slaughterhouses}

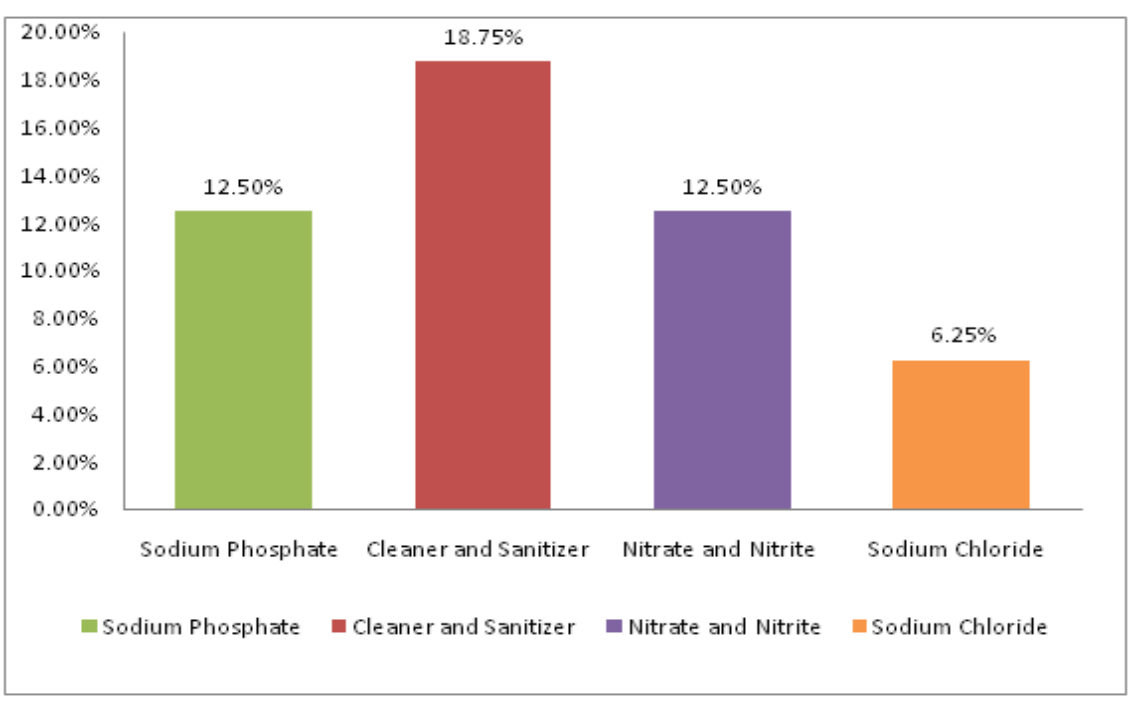

Figure 2: Percentages of each chemical used in meat

The figure- 2 above shows the percentage of each chemical used in slaughterhouses in case of meat. Among four chemicals cleaner and sanitizer shows the use in slaughterhouses of about $18.75 \%$, which is essential to clean and sanitize equipments and places. Nitrate $\&$ nitrite and sodium phosphate were used at level of about $12.50 \%$. According to the table sodium chloride was used at level of $6.25 \%$ of all slaughterhouses.

\section{CONCLuSion}

Levels of meat adulteration need to minimize to ensure food safety, consumer protection and generate better health among population. Meat adulteration risk found in this study including food defense incidents, intended to harm or commit food fraud motivated by economic gain is growing in scope, scale, and threat. The adulteration risks are direct, indirect, and technical. Public health vulnerability in each case is because the production operations are not following good manufacturing practices. Examples of fraud include misleading to consumers, carcinogenic preservatives and colorants in meat, unauthorized chemicals. To protect the consumers from these types of hazards Khulna City Corporation has to strengthen the activity regarding meat adulteration and also meat business association must investigate the process. Apart from this some other initiatives must be taken to encounter with meat adulteration. Such as: Public representatives (Councilors) should ensure their active participation to resist this dangerous phenomenon, Bangladesh Standard Testing Institution must take effective steps to ensure the quantity and the quality of meat, Government must ensure the activity of mobile court management regularly, Special guard should be increased on Fridays and festivals, Directorate of Consumer Rights Protection should ensure their activities properly etc. After adopting all the measures it is possible to lessen the practice of meat adulteration which will ensure the safety of food as well as secure the right to life of a human being.

\section{REFERENCES}

[1] http://www.businessdictionary.com/definition/food.html\#ixzz3HES8EAuf, accessed on 20/11/2017.

[2] Cohen, L. E., and Felson, M., (Aug., 1979). Social Change and Crime Rate Trends: A Routine Activity Approach. American Sociological Review. Vol. 44, No. 4, pp. 588-608.

[3] The Pure Food Ordinance, 1959 (East Pakistan Ordinance No. Lxviii of 1959).

[4] The Chambers Dictionary, Available at http://en.wikipedia.org/wiki/Chambers_Dictionary, accessed on $13 / 12 / 2017$.

[5] The World Food Summit of 1996 defined food security as existing "when all people at all times have access to sufficient, safe, nutritious food to maintain a healthy and active life". Available at http://www.who.int/trade/glossary/story028/en/, accessed on 18/11/2017

[6] WHO (2005). Preventing Chronic Diseases: A Vital Investment; Geneva: World Health Organization Retrieved from: http://apps.who.int/iris/bitstream/10665/43314/1/9241563001_eng.pdf.

[7] Barai, B. K., Nayak, R. R., Singhal, R. S., Kulkarni P. R. (1992). Approaches to the Detection of Meat Adulteration. Trends in Food Science \& Technology. Volume 3, pp. 69-72. 
[8] Sharma, BD. (1999). Meat and Meat Products Technology (Including Poultry Product Technology,) Jaypee- The Health Sciences Publisher.

[9] Shears, P. (2008). Food Fraud - A Current Issue but an Old Problem. Plymouth Law Review. Vol.1; pp. $118-139$.

\section{AUTHORS BIOGRAPHY}

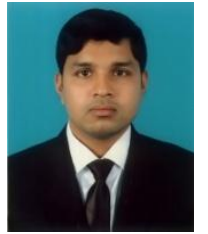

Md. Mahfuzur Rahman is a Lecturer at Department of Law of North Western University, Khulna, Bangladesh. He completed his LL.B. (Hon's) and LL.M. degree from the University of Rajshahi, Rajshahi, Bangladesh. He is also an advocate (nonpracticing) and a member of Dhaka Bar Association, Bangladesh. He has research interest on contemporary legal issues.

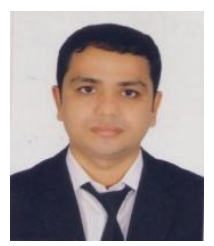

Hasibul Hossain Sumon did his LL.B. (Hon's) and LL.M. from the Department of Law of Rajshahi University, Rajshahi, Bangladesh. He is now teaching as Lecturer in the Department of Law at North Western University, Khulna, Bangladesh. His interests include both national and international legal issues.

Citation: Md. Mahfuzur Rahman, Hasibul Hossain Sumon. "Meat Adulteration at Khulna City of Bangladesh: A Criminological Analysis". International Journal of Humanities Social Sciences and Education (IJHSSE), vol 5, no. 4, 2018, pp. 109-115 doi: http://dx.doi.org/10.20431/2349-0381.0504013.

Copyright: (C) 2018 Authors. This is an open-access article distributed under the terms of the Creative Commons Attribution License, which permits unrestricted use, distribution, and reproduction in any medium, provided the original author and source are credited. 